\title{
MUDANÇAS ESTRUTURAIS NO CAPITALISMO E A POLÍTICA EDUCACIONAL DO GOVERNO FHC: O CASO DO ENSINO MÉDIO
}

JoÃo dOS REIS SILVA JÚNIOR*

\begin{abstract}
RESUMO: A proposta deste artigo é compreender o significado político da reforma educacional brasileira para seu nível médio e as consequiências para a formação do ser social, procurando mostrar a ciência instrumental e os supostos neopragmáticos presentes nos documentos oficiais que orientaram essa reforma, bem como as razões de ordem econômica que deram suporte para essas mudanças na esfera da educação.

Palavras-chave: Reforma do Estado. Mudança na produção. Reforma educacional. Política pública para o ensino médio. Neopragmatismo.
\end{abstract}

\section{STRUCTURAL CHANGES IN THE CAPITALISM AND EDUCATIONAL policies under Fernando Henrique Cardoso's administration: THE CASE OF MEDICAL TEACHING}

ABSTRACT: This paper aims at understanding the political meaning of the Brazilian educational reform for secondary education and its consequences on the development of social beings. It also intends to show the instrumental science and neo-pragmatic assumptions present in the official documents that oriented this reform, as well as the economical reasons that gave support to these changes in the sphere of the education.

Key words: State reform. Changes in production. Educational reform. Public policies for secondary education. Neopragmatism.

Professor titular da Universidade de Sorocaba e professor-pesquisador da Pontifícia Universidade Católica de São Paulo PUC-SP). E-mail: jrjunior@pucsp.br 


\section{Introdução}

E

m 1996, Valdemar Sguissardi e eu ${ }^{1}$ escrevíamos que o Brasil se tornara o país das reformas: econômica, tributária, fiscal, da previdência, produtiva, educacional etc., numa palavra, do Estado e da Constituição. Entendíamos essa cruzada reformista na qual se empenhava seriamente o governo de Fernando Henrique Cardoso como uma ação política estratégica para a aceleração das mudanças sociais necessárias à nação em face da matriz política, teórica e ideológica do projeto de governo de FHC, caracterizada centralmente pela dependência ao capital internacional. Para ilustrar tal esforço, citávamos o informe publicitário pago pelo governo, na Folha de S. Paulo de 8 de abril daquele ano. Desde logo chamava a atenção o slogan Estabilização e reformas ao lado da bandeira brasileira compondo com a manchete Sem reformas não há desenvolvimento e o texto abaixo:

Todo brasileiro quer viver em um país melhor. Um país com mais empregos, melhores salários, mais saúde, mais habitação, mais transportes, educação para todos. Um país mais desenvolvido e mais justo. O Brasil está avançando nessa direção. Primeiro foi o Plano Real, que controlou a inflação e estabilizou a economia. Agora, os brasileiros podem planejar a sua vida com mais tranqüilidade, e aqueles que ganham menos podem consumir mais. Mas isso não basta. É preciso avançar na direção do desenvolvimento e da melhoria das condiçôes de vida dos brasileiros. Para que isso seja possível, o governo elaborou um amplo programa de reformas que exigem mudanças na Constituição do país. A Reforma Econômica já foi aprovada pelo Congresso Nacional e significa o início da modernização do país. A abertura da economia e as privatizações vão permitir que a iniciativa privada substitua o Governo nas áreas onde ela for mais eficiente, como na siderurgia, nas ferrovias e na energia elétrica, entre outras. Isso se traduz em mais oportunidades e mais empregos. E vai permitir ao Governo investir nas áreas sociais, como saúde, educação, buscando a diminuição das desigualdades sociais. A Reforma da Previdência, além de assegurar os direitos de quem já está aposentado ou está para se aposentar, permitirá as primeiras conquistas na luta contra os privilégios e desigualdades do sistema. (...) Outras reformas também estão sendo encaminhadas para serem debatidas e votadas no Congresso Nacional. (...) O caminho do desenvolvimento brasileiro precisa de reformas. Com elas, cada um vai poder cumprir seu papel no futuro do país. E o Governo vai poder fazer a sua parte: assegurar o Plano Real e a estabilidade da economia e investir mais na área social, para os milhões de cidadãos do Brasil. ${ }^{2}$

Alertávamos ainda que a racionalidade orientadora do texto se assentava num pressuposto administrativo-eficientista: bastaria o 
governo promover certos ajustes e o país encontraria, feitas as reformas, o caminho da modernidade, via desenvolvimento. Com este, todos os problemas estruturais do Brasil seriam superados e a dignidade do cidadão, enfim, restabelecida. Completávamos, então, tratar-se de uma bela estória e uma forma simplista de se compreender as reformas institucionais. Pressupunha-se a existência de harmonia, estabilidade e continuidade de determinada situação social, que, com ajustes, tornar-se-ia democrática, justa e igualitária. $\mathrm{O}$ consenso, a democracia e o desenvolvimento constituem o núcleo desse discurso.

Passados aproximadamente sete anos e já no apagar das luzes dos dois mandatos presidenciais de Fernando Henrique Cardoso, vemos uma realidade bastante diferente daquela prometida no informe publicitário pago pelo erário público. Tão-somente aquilo que tornaria o Estado um órgão reprodutor do capital, "onde a iniciativa privada substituiria o governo para que este pudesse investir na área social", fora realizado, ao passo que na área social o que se viu foi a transformação do Estado em um Estado gestor, avaliador e caritativo, ainda assim sem ao menos atenuar a profunda crise social em que vivemos, provocada pela degradação de nosso processo civilizatório e pela banalização da vida humana. Ilustra o que afirmamos o editorial do Correio da Paraíba de 15/1/2002, sob o título Desigualdade social.

O Brasil, infelizmente, tem aparecido, em diversos levantamentos estatísticos, como um dos países de pior distribuição de renda. Esta situação, logicamente, o coloca também entre os piores em qualidade de vida. Em contrapartida, levando-se em consideração que o país conta com a décima economia mais desenvolvida do mundo, é de se lamentar a injustiça e a desigualdade social entre as classes sociais brasileiras. É um verdadeiro contraste, um choque de realidades entre as camadas cada vez mais pobres e as cada vez mais ricas. $\mathrm{O}$ absurdo das diferenças tem se transformado em números nada apreciáveis: cerca de um terço dos brasileiros vive na carência absoluta, enquanto os mais ricos ( $1 \%$ da população) são donos de parte maior do que sobra para os $50 \%$ mais pobres. Para a maioria dos cientistas sociais que criticam mais acirradamente a falta de política social mais intensa por parte do governo, uma das principais causas da desigualdade que mantém parcela da população na miséria absoluta é a falta de uma política educacional adequada à determinação constitucional de 1988, através do Plano Nacional de Educação. O PNE estabelece metas para todos os níveis e modalidades de ensino, orientando as ações do poder público nas três esferas da administração: União, Estados e Municípios. No entanto, se for 
para levar em conta a preocupação oficial com os investimentos na área da educação, o pessimismo continuará sobrepondo o otimismo, já que nada é feito neste sentido. Na contramão dos investimentos sociais, os banqueiros conseguiram empréstimos governamentais da ordem de $\mathrm{R}$ \$ 12,5 bilhões. Talvez porque os estrategistas econômicos acreditam serem os bancos mais importantes para o povo do que ter escolas funcionando eficientemente, com professores trabalhando dignamente e alunos assíduos, não apenas pela garantia da alimentação básica (merenda escolar), mas também em busca do desenvolvimento cultural que lhes dê maiores condições de concorrência num mercado de trabalho cada vez mais enxuto e exigente. Por fim, em se tratando de Brasil, a expansão da desigualdade social ainda tem contado com mais um fator determinante: o desvio de recursos financeiros. Muitas verbas que teriam de tomar um determinado caminho mudam de rota. Muitas vezes, caminhos diferentes mas legais; outras, caminhos e destinos ilegais que contam, em muitas ocasióes, com a complacência da total impunidade. (P. 2)

A sociedade civil já sente e denuncia os resultados do movimento reformista que se iniciou na segunda metade dos anos de 1990 na área social, particularmente na esfera educacional. Já se reivindica uma comissão parlamentar de inquérito para o Fundo de Manutenção e Desenvolvimento do Ensino Fundamental e de Valorização do Magistério (FUNDEF) e as próprias diferenças entre o Plano Nacional de Educação proposto pela sociedade civil (PNE-SC) e o que foi formulado pelo Poder executivo (PNE-FHC) mostram a racionalidade a que acima fizemos referência. $O$ PNE da sociedade brasileira (PNE-SC), como ficou conhecido o plano que se originou na sociedade civil, sustentava-se em dois grandes eixos: 1) a ampliação da ação do Estado na escola pública; e 2) a efetivação da gestão democrática da educação e da escola. Já o PNE-FHC, como ficou conhecido o plano concebido por iniciativa do governo, adaptava, em linhas gerais, as orientações para educação produzidas pelos assessores do Banco Mundial (Cf. Torres, 1996).

Como entender tais mudanças em uma realidade como a que é ilustrada pela apresentação de editorial e artigo publicados pela imprensa brasileira? Como lançar luz sobre a profunda transformação da esfera educacional em todos os seus níveis e modalidades operada por meio de reformas administradas por um Poder Executivo orientado pelos organismos multilaterais? Qual a orientação da linha de desenvolvimento desse movimento reformista que lançou o país em tal quadro degradante, em particular a educação? Como compreender a complacência e a ausência de indignação da sociedade civil 
organizada ou não? Como compreender, particularmente para o que aqui nos interessa, a reforma do ensino médio - que parece tão profissionalizante quanto a Educação Profissional de Nível Técnico (Cf. Ferretti e Silva Jr., 2000) - numa sociedade sem empregos e numa economia dependente do capital internacional sob a batuta de um Estado muito forte no plano nacional mas profundamente submisso no âmbito internacional? Esta é a pergunta central que buscaremos responder com este texto.

Bueno (2000, p. 8) oferece-nos a hipótese do "Palco Mal Iluminado":

O discurso governamental brasileiro deste final de século propala a instalação de um processo transformador fundado e construído no seio de um consenso nacional quanto à importância dos rumos da educação. Nessa perspectiva, o ideário educacional consubstanciado nos documentos oficiais estaria dotado, segundo seus defensores, de unidade e universalidade invejáveis que dispensam a análise crítica e, portanto, reparos de qualquer natureza. O que fundamenta essa certeza? Até que ponto o raciocínio unívoco impregna o cenário educacional e legitima políticas e ações governamentais?

$\mathrm{Na}$ verdade, tal consensualidade traduz o horizonte desenhado pelo movimento continental de concertación educativa preconizado para os países emergentes. ${ }^{3}$ Essa perspectiva orienta redefiniçōes progressivamente aperfeiçoadas no cenário educacional, em direção a um "pan-paradigma”, enquanto resistências e contraposições são desmobilizadas. Em contrapartida, o adesismo e a inércia contagiam focos de resistência. Assim, a diretividade o não-consenso - parece constituir o traço forte das transformações em andamento.

Não obstante a relevante afirmação acima, que aponta traços fundamentais do processo de reformas educacionais, é necessário responder a muitas outras perguntas. Entre elas, penso que seja crucial indagar sobre a necessidade da construção de um pacto social mundializado para o que concorreria o "pan-paradigma" educacional. Uma, dentre muitas formas de construção da resposta a essa questão parece pôr-se a partir da inserção das reformas educacionais "sob o prisma de ajustes estruturais" como se lê na Declaração de Nova Delhi, da qual o Brasil é signatário, destacada por Bueno em nota de rodapé. Isso implica buscar entender a reforma educacional para o objetivo deste texto, no caso, a do ensino médio como uma ação política para mudança social tendo como elementos, que fundam essas mudanças, a economia e o trabalho nos países emergentes. 
Dessa perspectiva, pois, é que buscaremos entender as políticas públicas para esse nível de ensino no marco da reforma educacional mercantil que se consolida no país nos moldes da extended order como preconizava Hayek na década de 40 do século XX.

Defendemos, assim, que as reformas educacionais na América Latina, particularmente no Brasil, são uma intervenção consentida realizada pelas autoridades educacionais nos moldes das agências multilaterais, no contexto da universalização do capitalismo, direcionadas por uma razão instrumental e pela busca de consenso social geral, que se constitui no epicentro de um processo de mercantilização da esfera política, em geral, em particular da esfera educacional - locus privilegiado para o Estado de formação do ser social, portanto, de construção de um novo pacto social.

\section{Os documentos políticos e a construção da} concertación: Neopragmatismo e ciência engajada

No início da década de 1990, no mandato de Itamar Franco, tendo como ministro da Educação e do Desporto Murílio de Avellar Hingel, por iniciativa do governo, teve lugar a organização de um movimento em prol da valorização da educação, no contexto das reuniōes mundiais organizadas pela UNESCO, em geral com financiamento e assessoria do Banco Mundial. Um dos resultados desse sério esforço foi a publicação pelo MEC, "realizada dentro do Acordo mec/unesco", do texto Plano Decenal de Educação para Todos. Ele é apresentado pelo ministro da Educação em maio de 1994 e dirigido diretamente "Aos Professores e Dirigentes Escolares", dispensando as necessárias mediações de outras instâncias, tais como as secretarias estaduais, associações docentes, profissionais e científicas. Tal apresentação já mostra o caráter privado de construção da concertación, sem discussão com coletivos, que vinham refletindo sobre os caminhos da educação brasileira. Em certo sentido ilustra o que em outros textos chamamos de hiperpresidencialismo, isto é, a hipertrofia do Poder Executivo em detrimento do Legislativo e do Judiciário. E, a prática de relações entre o Estado e a sociedade civil sem mediaçôes políticas realizadas por aquelas entidades. Isso por si já indica o início da construção de um novo paradigma político, em cujo centro se encontra a legitimidade da ciência posta em prática por especialistas e orientada pela razão instrumental. 
Em seguida à apresentação, o documento traz o "RoteiroSugestão para Discussão do Plano Decenal nas Escolas", tendo como documentos de referência: a) Declaração Mundial sobre Educação para Todos; b) Plano de Ação para Satisfazer as Necessidades Básicas de Aprendizagem; c) Plano Decenal de Educação para Todos; d) Plano Decenal Estadual de Educação para Todos; e) Plano Decenal Municipal de Educação para Todos; e f) Arquivos da Escola. A primeira impressão que se tem é a de que se prevê uma gestão autônoma de cada escola, cujo funcionamento estivesse atendendo aos objetivos da comunidade onde ela se inseriria, com apoio e sem intervenção central. Ledo engano e eficiente produção ideológica perceptíveis quando se analisam os documentos de referência e outros que resultaram das açōes da UNESCO no plano mundial e regional como a Declaração de Nova Delhi (também parte do documento) e o famoso Educación y conocimiento: Eje de la transformación productiva con equidad, da Cepal/Orealc.

Destaca-se ainda, como parte do Plano Decenal de Educação para Todos, o Compromisso Nacional de Educação para Todos, firmado pelos participantes da Semana Nacional de Educação para Todos, reunidos em Brasília-DF de 10 a 14 de maio de 1993, com vistas a orientar a construção do Plano... O evento foi coordenado pelas autoridades: Murílio de Avellar Hingel, ministro da Educação e do Desporto; Maria Aglaê de Medeiros Machado, secretária de Educação Fundamental; José Carlos de Almeida Silva, presidente do Crub; Heldon Vitor Malatinho, presidente do Fórum dos Conselhos Estaduais de Educação; Miguel Angel Enriquez, representante da UNESCO no Brasil; Walfrido Mares Guia, ${ }^{4}$ presidente do CONSED; Olindina Olivia Correa Monteiro, presidente da UnDIME; e Maria de Fátima Guerra de Sousa, diretora de Faculdade de Educação; e assinam tal compromisso aproximadamente 130 participantes, incluindo essas autoridades, em sua grande maioria representantes das secretarias estaduais de Educação, de delegacias de ensino, dos conselhos estaduais de Educação e de outras entidades desde universidades até a Confederação Nacional das Indústrias e a Varig.

O Plano Decenal de Educação para Todos é a expressão brasileira do movimento planetário orquestrado por UNESCO, BIRD/Banco Mundial e assumido pelo Brasil como orientador das políticas públicas para a educação que resultaram na reforma educacional brasileira dos anos de 1990, realizada em todos os níveis e modalidades, com diretrizes curriculares, referenciais curriculares, Parâme- 
tros Curriculares Nacionais para níveis e modalidades de ensino, produzidos estes de forma competente por especialistas - em geral pesquisadores e professores universitários - de nossas melhores universidades e instituições de pesquisa, afinados com o compromisso assumido pelas autoridades políticas brasileiras em todas as áreas de ação do Estado, particularmente para a educação. Tal modus operandi é típico do que chamamos de hiperpresidencialismo e da lógica do novo paradigma político que se inaugurava no Brasil depois do processo de desgaste imposto aos canais políticos de mediação entre Estado e sociedade civil nos anos de 1980. Ilustra bem o que foi a década de 1980, no âmbito da economia, este depoimento feito em palestra por Perry Anderson:

Recordo-me de uma conversa que tive no Rio de Janeiro, em 1987, quando era consultor de uma equipe do Banco Mundial e fazia uma análise comparativa de cerca de 24 países do Sul, no que tocava a políticas econômicas. Um amigo neoliberal da equipe, sumamente inteligente, economista destacado, grande admirador da experiência chilena sob o regime de Pinochet, confiou-me que o problema crítico durante a presidência de Sarney não era uma taxa de inflação demasiado alta - como a maioria dos funcionários do Banco Mundial tolamente acreditava -, mas uma taxa de inflação demasiado baixa. "Esperemos que os diques se rompam", ele disse, "precisamos de uma hiperinflação aqui, para condicionar o povo a aceitar a medicina deflacionária drástica que falta neste país". Depois, como sabemos, a hiperinflação chegou ao Brasil, e as conseqüências prometem ou ameaçam - como se queira - confirmar a sagacidade deste neoliberal indiano. (Anderson, 1995, p. 22)

O movimento que resultou no Plano... mostra de forma clara o papel de alguns de nossos intelectuais na legitimação desse novo paradigma político em cujo centro se encontra a ciência em uma redução instrumental e não-reflexiva. Afirma-se isso porque se trata da ciência que não faz a crítica de forma distanciada, mas da ciência engajada em um projeto político, portanto instrumental, e produzida para o fim desse projeto político, o que possibilitou construir tal consertación com certa facilidade entre a maioria da sociedade brasileira, no contexto pós-década de 1980, quando a crítica passou a ser desqualificada em vez de debatida e os críticos passaram a ser classificados pelo presidente da República de neobobos. Depois dos anos de 1980 e com esse movimento assim produzido, ainda que pouco tenha ficado do documento em si, o caminho dos especialistas das diversas áreas de atividade humana administradas no âmbito do Estado estava pavimentado para que as famosas reformas prometidas em 1996, de 
fato, passassem à prática, como se viu, bem como os seus nefastos resultados. Reformas brasileiras que expressariam na sua especificidade o paradigma político produzido no âmbito mundial, já comentado acima.

A palavra aprendizagem tornara-se a pedra filosofal em qualquer documento ou programa educacionais. O império da exclusividade cognitivista construiu-se, possibilitando o aporte teórico para pedagogias instrumentais e adaptativas, por meio da naturalização das condições sociais.

A educação, esfera formativa do ser social, passa a expressar o novo paradigma político centrado no epistêmico e na busca do consenso, e toma a realidade social e natural como dada. Elas são, dessa forma e por alguma razão, de ordem metafísica e qualquer conflito deve ser superado num consenso produzido por intermédio da democracia comunicativa, sem questionamentos das contradições que produzem nossa realidade social por meio de relações sociais que se materializam em práticas sociais de qualquer tipo. A educação parece organizar-se segundo os fundamentos do neopragmatismo, isto é, importa a convenção a que se chega por meio da linguagem à justificativa de uma prática social. Enfim, a busca de um consenso geral por meio da justificação das crenças seria a essência da democracia. Nas palavras de Richard Rorty:

A afirmação "o pragmatismo é incapaz de dar conta do caráter absoluto da verdade" confunde duas demandas: a de explicarmos a relação entre nossas afirmações de crenças verdadeiras e o mundo, e a exigência especificamente epistemológica de uma certeza presente, ou de um trajeto garantido que nos leve até à certeza, ainda que apenas num futuro infinitamente distante. A primeira é tradicionalmente atendida dizendose que é o mundo que torna nossas crenças verdadeiras, e que elas correspondem ao jeito como as coisas realmente são. (Rorty, 2000, p. 36-37; grifos nossos)

Note-se nesse excerto como a realidade social contraditória, histórica e produzida pela atividade humana é negada e é tomada como algo dado que justifica nossos valores, nossas crenças, bastando, por meio da linguagem, encontrarmos a justificação adequada para fortalecer a crença do indivíduo. Trata-se de um movimento teórico de adaptação às mudanças sociais, sem questionar as razões dessas transformações. Continua o autor:

(...) devemos desistir da idéia de que o conhecimento é uma tentativa de representar a realidade. Ao invés disso, deveríamos ver a investigação 
como uma maneira de usar a realidade. Assim, a relação entre nossas afirmações verdadeiras e o resto do mundo é causal ao invés de representacional: ela causa em nós a manutenção de certas crenças, e nós mantemos as crenças que se provam como guias confiáveis para conseguir o que queremos. (Idem, ibid.; grifos nossos)

Importa, como diz Moraes (2001), analisando Rorty, mais a convenção social para aproveitar-se da realidade social e da natureza do que o conhecimento e a verdade, esta última medida pelo sucesso alcançado, especialmente pelo trabalhador, na sociedade em geral e no mercado de trabalho em particular. $O$ conhecimento orientado pela existência humana cede lugar à instrumentalização pelo social naturalizado por meio das convençóes que orientam a existência humana. Parece que, de fato, a ciência tornou-se meio de produção, e, nesse movimento, transformou o paradigma político, colocando em seu centro a racionalidade científica e instrumental, do que derivariam os critérios convencionados no âmbito da reprodução social da vida humana, apresentando-se o "relativismo rortyano" na condição de grande síntese do momento histórico por que passamos e que orienta as reformas educacionais que se fizeram em profusão pelo mundo nos anos de 1980 , e, no Brasil, nos de 1990.

O novo paradigma político, assentado no epistêmico, no cognitivo e no neopragmatismo, pode ser observado como fundamento nos documentos políticos oficiais, no Plano Decenal de Educação e nos seus "Documentos de Referência”, acima citados. A título de exemplo vejamos trechos de alguns documentos.

A Declaração Mundial sobre Educação para Todos - Plano de Ação para Satisfazer as Necessidades Básicas de Aprendizagem, em seu "Preâmbulo", expressa a preocupação política com as "mais de 100 milhões de crianças, das quais 60 milhões são meninas, não [terem] acesso ao ensino primário"; com os "mais de 960 milhões de adultos - dois terços dos quais mulheres, são analfabetos, (...) [sendo o] analfabetismo funcional um problema significativo em todos os países industrializados ou em desenvolvimento"; com mais de "um terço do mundo [que] não tem acesso ao conhecimento impresso, às novas habilidades e tecnologias, que poderiam melhorar a qualidade de vida e ajudá-los a perceber e a adaptar-se às mudanças sociais e culturais", sedutoras preocupações políticas que sensibilizaram muitos políticos e educadores bem-intencionados mas também os oportunistas. 
Destacam-se, no entanto, algumas ponderações com base no que até agora expusemos sobre o "pan-paradigma” educacional. O documento é movido pelas grandes transformações em curso no momento atual, mais do que com a formação não reificada do ser humano. Orienta-se pelas "mudanças sociais e culturais" em "países industrializados ou em desenvolvimento", em acréscimo, essa educação foca os desvalidos sociais, sem pôr em pauta as razôes dessa condição, para ajudá-los a "perceber e a adaptar-se às mudanças sociais e culturais" em trânsito em todos os países.

Ainda, qualifica os países em "industrializados ou em desenvolvimeto". Tal qualificação não é tão-somente uma questão de léxico, mas de perspectiva e de objetivos. Depreendem-se, desde logo, os fundamentos neopragmáticos aí expressos: importa usar a realidade social e cultural em mudança para fortalecer as crenças dos seres sociais e tomá-las como guia para o sucesso na sociedade e no trabalho por meio da percepção dessas mudanças e da adaptação a elas por intermédio das habilidades e tecnologias, da justificação das "crenças verdadeiras", pois é "o mundo que torna nossas crenças verdadeiras, e que elas correspondem ao jeito como as coisas realmente são". Tratase, pois, de preocupações políticas com a educação dos desvalidos, que se ancoram no neopragmatismo e na busca do consenso, na adaptação e na continuidade da racionalidade que preside a atual reprodução social da vida humana, utilizando-se como meio para a formação do indivíduo o desenvolvimento de habilidades e a percepção e não o conhecimento da realidade e das mudanças sociais e culturais.

A análise do dez artigos que compõem o tópico Declaração Mundial... permitiria adensar o que acima indicamos quanto à expressão do novo paradigma político e sua tradução na esfera da educação, no marco das grandes transformaçôes ainda em curso do capitalismo em âmbito mundial. No entanto, remetemos o leitor ao próprio documento, que explicita tais pressupostos por si.

O documento da Comissión Economica para América Latina y Caribe e Oficina Regional de Educación para América latina e Caribe, Educación y conocimiento: Eje de la transformación com equidad, de 1992, é a tradução teórico-reducionista da Declaração Mundial... para a América Latina e o Caribe, na medida em que parte de um determinismo tecnológico e propõe de forma precisa e explícita a subordinação educacional à economia. Basta que se leia abaixo o excerto destacado no próprio documento, que também põe em relevo os jovens trabalhadores e a educación secundaria. 
Los estudios de los nuevos modos de organización del trabajo en las empresas manufactureras revelan que se han agregado nuevos requisitos educacionales y que estos, a su vez, definen un nuevo perfil del obrero. La introducción de nuevos procesos de producción exige a los operarios poseer tres nuevas aptitudes: en primer lugar, la capacidad de cumplir en forma simultanea de la calidad del producto, y de plazo de producción (fecha de entrega); segundo, la capacidad de encargarse, como parte de un equipo, de regular flujos de producción, tanto en función de la demanda, como de la necesidad de optimizar el uso de los recursos humanos e instalaciones físicas de que dispone la firma en un momento dado; en ese contexto, los obreros pasan a asumir buena parte de las funciones que antes desempeñaban los supervisores, finalmente, los mismos obreros se ven asociados a actividades conceptuales, pues deben contribuir activamente a la aplicación y al afinamiento de procesos de producción que están cambiando continuamente.

El nuevo perfil no elimina los requisitos anteriores de formación técnica práctica, sino que agrega la exigencia de tener mayores capacidades de evaluación analítica y manejo conceptual y aptitudes para verbalizar y transmitir información, que exceden el conocimiento intuitivo anteriormente considerado crucial en la formación obrera. Las últimas condiciones para desempeñarse bien son la flexibilidad y la capacidad de asimilar nuevas normas y situaciones. (P. 84; grifos nossos)

Como se pode notar nesse excerto, a nova formação do trabalhador e do cidadão é conformada pelas demandas postas pelas novas tecnologias de base física ou organizacional e o novo ser social trabalhador, formado por meio da educação escolar, deve conhecer simultaneamente a qualidade do produto e do processo, bem como a produtividade da produção; deve possuir habilidades de gestão e espírito para o trabalho em equipe, bem como a sensibilidade para, com base em seus saberes explícitos e tácitos, refinar a qualidade do processo de trabalho.

Isso implica, como podemos observar em destaque na citação, a formação de um trabalhador que tenha um processo cognitivo capaz de lidar com conceitos, trabalhar bem as informações, comunicar-se para poder estar apto a resolver qualquer problema inesperado ou adaptar-se a qualquer situação que se apresente. Interessante a demanda de um novo trabalhador que saiba o seu trabalho, saiba fazer seu trabalho, mobilizar todo seu ser para realizar o trabalho e seja versátil para se sair bem em qualquer situação, num contexto de imprevisibilidade. Isso nos lembra o Relatório para a UNESCO da Comissão Internacional sobre a Educação para o Século XXI, preparado por comissão liderada por Jaques 
Delors em seus princípios: a) aprender a conhecer (saber); b) aprender a fazer; c) aprender a viver juntos (aprender a viver com os outros); e a inconsistente máxima: d) aprender a ser. ${ }^{6}$

Notamos as orientações do novo paradigma político fundado no neopragmatismo e na ciência instrumentalizada, aquela que é útil para usar a realidade e nos mostrar quais crenças são nossos melhores guias para obtenção do sucesso, para obtenção de um futuro melhor, tomando, como já analisamos anteriormente, a realidade social como algo dado ou construído por uma entidade metafísica. Esses seriam os fundamentos da educação em geral para o século XXI, mais particularmente para o ensino médio, para os jovens. Como se pode ler em Delors (1996):

Dado que oferecerá meios, nunca antes disponíveis, para a circulação e armazenamento de informaçōes e para a comunicação, o próximo século submeterá a educação a uma dura obrigação que pode parecer, à primeira vista, quase contraditória. A educação deve transmitir, de fato, de forma maciça e eficaz, cada vez mais saberes e saber-fazer evolutivos, adaptados à civilização cognitiva, pois são as bases das competências do futuro. Simultaneamente, compete-lhe encontrar e assinalar as referências que impeçam as pessoas de ficar submergidas nas ondas de informações, mais ou menos efêmeras, que invadem os espaços públicos e privados e as levem a orientar-se para projetos de desenvolvimento individuais ou coletivos. $\grave{A}$ educação cabe fornecer, de algum modo, os mapas [guias seguros] de um mundo complexo e constantemente agitado e, ao mesmo tempo, a bússola que permita navegar nele [fazer uso dele]. (Delors, 1996, p. 89)

Gramsci, em seu brilhante ensaio Americanismo e fordismo, já alertava para a necessária unidade entre a formação para o trabalho e a formação de um novo ser social. Lukács chama atenção para o entendimento de uma determinada esfera social específica como a educação, para a necessidade de compreender-se a racionalidade do movimento social em geral, que, ao seu turno, assenta-se nos elementos que fundam a reprodução social: a economia e a natureza. Ou, ainda, como se encontra na Declaração de Nova Delhi, da qual o Brasil é signatário, a convocação para que "as instituições financeiras internacionais (...), sob o prisma dos ajustes estruturais, reconheçam a educação como investimento crítico isento da imposição de tetos preestabelecidos e que promovam um clima internacional capaz de permitir aos países sustentar seu desenvolvimento socioeconômico”. Acrescentamos a inteligente observação de Coraggio (1996) sobre uma das principais instituiçôes financeiras internacionais: um dos possíveis sentidos das políticas sociais do Banco Mundial é 
(...) instrumentalizar a política econômica, mais do que continuá-la ou compensá-la. São [as políticas sociais] o "Cavalo de Tróia" do mercado e do ajuste econômico no mundo da política e da solidariedade social. Seu principal objetivo é a reestruturação do governo, descentralizando-o ao mesmo tempo em que o reduz, deixando nas mãos da sociedade civil competitiva a alocação de recursos, sem a mediação estatal. Outro efeito importante é introjetar nas funçōes públicas os valores e critérios do mercado (a eficiência como critério básico, todos devem pagar pelo que recebem, os órgãos descentralizados devem concorrer pelos recursos públicos com base na eficiência da prestação de serviços segundo indicadores uniformes etc.), deixando como resíduo da solidariedade a beneficência pública (redes de seguro social) e preferencialmente privada, para os miseráveis. Em conseqüência, a elaboração das políticas setoriais [como as políticas públicas para a educação] fica subordinada às políticas de ajuste estrutural, e freqüentemente entra em contradição com os objetivos declarados. (Coraggio, 1996, p. 78-79; grifos nossos)

Essas argumentações nos alertam para a necessidade de compreendermos os elementos que fundam esse novo paradigma político em cujo centro se encontra a ciência engajada e instrumental, fundado em supostos neopragmáticos e na possibilidade da construção de um novo pacto social mundializado para o que concorreria fortemente o "pan-paradigma" educacional, produzido por meio de uma concertación a orientar as reformas educacionais no âmbito planetário e no Brasil. Ainda, que a degradação do processo civilizatório e a banalização da vida humana possam ser vistas cotidianamente em tempo real. Assim, as contradições da racionalidade do movimento da realidade social ajudam-nos a entender a atual conjuntura brasileira e a instrumentalização educacional ilustradas no início do texto, como se pode depreender da citação imediatamente anterior.

\section{A universalização do capitalismo, trabalho e educação}

A racionalidade das mudanças na esfera educacional é o resultado de suas inter-relações com as demais esferas sociais das práticas humanas e dessas com as transformaçōes gerais da sociedade. No entanto, o movimento geral da sociedade é um momento predominante. Porém, se a racionalidade que orienta o movimento geral é predominante e tem relativa autonomia sobre os elementos que o fundam, é preciso afirmar, segundo Lukács, que tal autonomia da reprodução social é, de fato, relativa, pois a compreensão da linha de desenvolvimento da sociedade em seu todo só é possível se 
entendermos o movimento dos seus elementos basilares, nesse caso, a economia e o trabalho. Dessa forma, faz-se necessário o entender as mudanças na economia e no trabalho nesses últimos anos do capitalismo e a sua expressão no Brasil.

O novo modelo que se inaugura nos anos de 1970 transcende a internacionalização da economia como se entendia no início do século XX. Trata-se de sua mundialização, da universalização do capitalismo. Segundo Chesnais (1996, p. 51), existem três dimensões principais para a realização de tal processo: "intercâmbio comercial, investimento produtivo no exterior e os fluxos de capital monetário, ou capital financeiro", e acrescenta que "as relações entre essas três modalidades de internacionalização devem ser buscadas no nível das três formas ou ciclos da movimentação do capital, definidos por Marx: o capital mercantil; o capital produtor de valor e de maisvalia; e o capital monetário ou capital-dinheiro".

Chesnais (1996), citando Michalet (1985), afirma que essa abordagem permite mostrar a passagem da internacionalização da economia, com base no comércio exterior e nos fluxos de capital monetário e financeiro, para a economia mundializada, por sua vez ancorada na mundialização do capital produtor de mais-valia, ou seja, do capital produtivo. $\mathrm{O}$ aumento do investimento externo direto (IED) e as conseqüências qualitativas daí derivadas na reorganização das economias nacionais e mundial, e, especialmente, nas grandes corporações transnacionais, provocam uma mudança no paradigma tradicional. Segundo Michalet (1985):

No paradigma tradicional, o capital produtivo fica colocado por fora da mundialização do capital. A transformação da economia internacional em economia mundial coincide com o fim dessa dicotomia. A mundialização do capital produtivo torna-se parte integrante da mundialização do capital. (Michalet, 1985, apud Chesnais, 1996, p. 309)

Acrescenta Chesnais (1996): "Mais exatamente, torna-se o centro dela" (a mundialização do capital). Na década de 1980 a mundialização do capital produtivo ou investimento externo direto (IED) sofreu um aumento significativo, especialmente, no início desses anos, declinando atenuadamente no final dessa década. No entanto, para além dos aspectos quantitativos do IED na economia mundial, seus aspectos qualitativos parecem realmente colocá-lo no centro da mundialização do capital. Para Chesnais (1996), citando H. Bourguinat (1992), são quatro as principais razões: 
Em primeiro lugar, diferentemente do comércio exterior, o IED "não tem uma natureza de liquidez imediata (pagamento à vista) ou diferida (crédito comercial)". Não se reduz a uma transação pontual. Pelo contrário, sua segunda característica é introduzir uma "dimensão intemporal" de grande importância, pois a "decisão de implantação dá origem a fluxos (produção, comércio, repatriação de lucros) que se estendem, necessariamente, por vários longos períodos". A terceira particularidade é "implicar transferências de direitos patrimoniais e, portanto, de poder econômico, sem medida comum à simples exportação". "Por último" [e talvez mais importante], diz Bourguinat, "existe um componente estratégico evidente na decisão de investimento da companhia. Não somente seu horizonte é sensivelmente mais amplo, como também as motivações subjacentes são muito ricas (...) a idéia de penetração, seja para depois esvaziar os concorrentes locais, seja para 'sugar' as tecnologias locais, faz parte desse aspecto 'estratégico' do investimento direto e, geralmente, está inserido num processo complexo de tentar antecipar as ações e reaçoes dos concorrentes". Ressalte-se o uso do termo "sugar" (siphonner), pouco habitual entre os economistas acadêmicos. Esse termo remete à existência, no contexto de estruturas concentradas, de mecanismos de apropriação e de centralização, pelas companhias mais fortes, de ativos ou riquezas produzidos por agentes econômicos (além de assalariados, claro); no caso, pequenas empresas industriais, comerciais ou de pesquisa, cuja existência é reconhecida por poucos autores acadêmicos. (Chesnais, 1996, p. 54)

Nesse contexto de mundialização da economia, tendo como estratégia central não mais somente o comércio exterior e o capital financeiro, mas, antes, o capital produtivo por meio do investimento externo direto, emerge um novo paradigma de empresa, com novas estruturas corporativas, novas formas organizacionais, novas formas de gestão, assentadas em nova base produtiva, possibilitadas, nesse último caso, pelas atuais tecnologias produzidas no âmbito da terceira revolução tecnológica. Por outro lado, pode-se depreender da citação acima a razão das desnacionalizações das economias periféricas e a reestruturação do mercado de trabalho e sua desregulamentação no âmbito do Estado, como por exemplo, a "flexibilização das relações trabalhistas". Disso decorre a necessidade de profundas mudanças nas estruturas sociais, portanto, de nova forma de politização da sociedade (reformas políticas e do Estado), da nova formação do ser social, para o que a educação, desse prisma, tem para si igual demanda, ou seja, profundas mudanças (reformas educacionais).

Afirma Chesnais (1996), citando Michalet, a emergência de um "novo estilo" denominado tecno-financeiro:

(...) de internacionalização baseada nos ativos intangíveis da companhia, no seu capital humano. E Michalet precisava: "A estratégia tecno- 
financeira é o resultado de uma evolução das atividades das companhias no exterior, passando da produção material direta para o fornecimento de serviços. A base de sua competitividade está alicerçada na definição de um know-how e na P\&D. Ela tentará valorizar essa vantagem em todos os setores onde for possível aplicar suas competências tecnológicas. Com isso, ela tenderá a sair do seu setor de origem e diversificar-se em modalidades totalmente originais. Sua nova força reside em sua capacidade de montar 'operações complexas', [que] irão exigir a combinação de operadores vindos de horizontes muito diferentes: empresas industriais, firmas de engenharia, bancos internacionais, organismos multilaterais de financiamento. Destes, uns serão locais, outros estrangeiros, outros terão estatuto internacional". (Chesnais, 1996, p. 59-60)

Chesnais (1996), citando Dunning (1988), complementa que essas corporações seriam:

(...) o sistema nervoso central de um conjunto mais amplo de atividades, interdependentes mas gerenciadas menos formalmente, cuja função primordial consiste em fazer progredir a estratégia concorrencial global e a posição da organização que está no âmago (core organization). (...) Não é apenas, ou mesmo principalmente, pela organização mais eficiente de sua produção interna e de suas transaçôes, ou por suas estratégias de tecnologia de produtos e de comercializaçoes, que essa organização atinge seu objetivo, e sim pela natureza e forma das relaçôes que estabelece com outras empresas. (Chesnais, 1996, p. 77)

No atual contexto da economia mundializada, ainda que o investimento externo direto seja o centro dessa nova ordem econômica, a força do capital monetário ou financeiro faz-se presente na estruturação do novo paradigma corporativo que vimos descrevendo acima. $\mathrm{O}$ monetarismo assume determinado lugar de macrogestão econômica em nível mundial, influenciando largamente as estruturas das grandes companhias mundialmente organizadas.

O "objetivo", mais que nunca, é o lucro, ao qual se soma, em combinações variáveis de um capitalismo "nacional" para outro, o objetivo de crescer e durar. Com efeito, no quadro da mundialização financeira, (...) o rendimento financeiro dos ativos é vigiado pelos detentores de carteiras de açōes, e tanto mais de perto, na medida em que esses são, cada vez mais freqüentemente, grandes investidores institucionais (fundos de pensão, grupos de seguros gerindo carteiras de ativos importantes etc.), e que têm a possibilidade de comparar tal rendimento com o de ativos financeiros puros. $\mathrm{O}$ grupo multinacional, então, precisa ser eminentemente rentável, mas atualmente essa rentabilidade não pode mais ser baseada unicamente na produção e comercialização próprias do grupo e de suas filiais. Precisa basear-se [antes de tudo] nas suas "relações com outras empresas". (Chesnais, 1996, p. 77)

Educ. Soc., Campinas, v. 23, n. 80, setembro/2002, p. 201-233 
Do afirmado acima, pode-se depreender que as fronteiras entre lucro e renda tornam-se cada vez mais fluidas, com conseqüências cada vez mais fortes para a consolidação do novo paradigma organizacional das grandes corporações em nível mundial, obrigando-as ao estabelecimento de relaçôes mais consolidadas com outros grupos, empresas de variados portes em nível planetário.

A multiplicação das participações minoritárias de companhias “coligadas”, das participações em cascata e, sobretudo, de numerosos acordos de terceirizaçôes e de cooperação interempresas, que levaram ao surgimento das chamadas "empresas-rede", não teve como único efeito tornar muito permeáveis e indistintas as fronteiras da companhia. Também acarretou a incorporação, ao lucro, de receitas que se resolvem em créditos sobre a atividade produtiva de outra companhia, sob a forma de punções sobre seus resultados de exploração brutos. Essa dimensão é particularmente fácil de se perceber nas "novas companhias de investimentos". (Chesnais, 1996, p. 78)

Podemos depreender do que até agora se expôs que a universalização do capitalismo trouxe a novidade da internacionalização do capital produtivo, o que impôs um novo paradigma estrutural, organizacional e de gestão para as grandes corporações, bem como, no plano macroeconômico, induziu o movimento de fusôes corporativas como temos observado. Por outro lado, isso impôs um novo metabolismo social cuja racionalidade é a penetração do capital em quase todas as esferas, especialmente aquelas que outrora eram de natureza pública, movimento que se iniciou pela própria reforma do Estado, que passa a gerir novas reformas, incluindo aí as educacionais, com o objetivo de iniciar e consolidar as mudanças sociais nesse novo estágio do capitalismo.

São ações políticas operacionais orientadas, por sua vez, por um novo paradigma político já caracterizado no item anterior, que é parte do atual metabolismo social (Cf. Mézáros, 2002, especialmente p. 94-174). O Estado caracteriza-se, nesse processo, pela lógica eficientista, realizando-se por essa razão em seu âmbito um movimento que restringe a esfera pública e produz, por meio de uma nova regulamentação ancorada no cientificismo instrumental e em valores mercantis (Cf. Sguissardi e Silva Jr., 2001, especialmente o capítulo II), a necessária politização da sociedade. Isso se dá mediante políticas públicas de mesma orientação e pela reorientação das práticas sociais por intermédio de instituiçóes como a escola.

Dessa maneira isso também se põe para a esfera educacional como já se viu. A esfera educacional reconfigura-se nesse processo, assumindo 
a mesma orientação, como pudemos ler nos documentos internacionais nos âmbitos global, latino-americano e nacional. Assim é possível compreender, sempre considerando a autonomia relativa da atual forma histórica de reprodução social da vida humana, a racionalidade do movimento social, que se faz presente nas reformas do Estado e da educação, especialmente no ensino médio, pelas demandas que a este nível e modalidade são postas e pelo fato de estarem aí os jovens prestes a entrar no mercado de trabalho e a ter uma inserção social mais efetiva. Dessa maneira, a reforma educacional nesse nível de ensino parece ser a mais complexa, e, ao mesmo tempo, central para os reformistas, posto que aqueles constituirão as futuras gerações a darem materialidade ao pacto social mundializado que estes buscam produzir.

\section{A reforma do ensino médio}

Bueno indaga sobre a ausência do debate e do necessário dissenso no discurso e nos documentos sobre o ensino médio e sobre a condição "infalível” das propostas políticas do Estado para o nível de ensino em questão, ao que acrescento indagações sobre a truculência do Poder Executivo em relação à reforma educacional para o ensino médio e sobre a adesão de muitos educadores aos apelos do governo em seu esforço para a mudança da esfera da educação.

Também procuramos inquirir sobre o significado da reforma para o ensino médio, no contexto das transformaçôes gerais por que passa o capitalismo há mais de três décadas e sua expressão no âmbito nacional. Por isso, procuramos mostrar, ainda que de forma breve, as relações entre a mudança das estruturas sociais, os elementos que sustentam tal mudança, a transformação de paradigma político e a reforma educacional.

Falta-nos mostrar como esse movimento toma forma histórica no ensino médio, ou seja, como os pressupostos cognitivistas e neopragmáticos, e a razão instrumental põem-se para o ensino médio, tornando-o tão profissionalizante quanto a educação profissional de nível técnico. Para isso, nos utilizaremos do Parecer no $15 /$ 98, que, entre outras providências, estabelece as Diretrizes Curriculares Nacionais para o Ensino Médio e os Parâmetros Curriculares Nacionais para o Ensino Médio. Temos consciência de que a tradução das normas para a prática escolar é socialmente produzida por uma multiplicidade de mediações e que o resultado será sempre diferente do que fora proposto a priori. 
No entanto, a própria existência dos documentos elaborados por especialistas, parcialmente discutidos com a academia e a sociedade, aprovados pelos órgãos normativos oficiais de um Estado que se transformou em gestor, avaliador e caritativo na área social, bem como as muitas decisóes que disso decorreram, são suficientes para fornecer materialidade com base na qual se pode iniciar o entendimento das políticas para o ensino médio, e posto que todo esse processo já era parte orgânica da reforma educacional.

O Parecer no 15/98 da Câmara de Educação Básica do Conselho Nacional de Educação, que trata das Diretrizes Curriculares Nacionais para o Ensino Médio, acompanha de forma clara e explícita os documentos produzidos pelas iniciativas da UNESCO, em geral com financiamento do Banco Mundial, citando-os em momentos oportunos como argumentos de autoridade. $\mathrm{O}$ documento apresenta uma orientação tecnicista, ainda que argumente sobre a necessidade de contextualização da análise, para a produção das diretrizes, ignorando toda a complexa transformação e sua forma histórica de realizar-se tal como buscamos mostrar até agora neste artigo.

Não se pode falar que esse documento em sua leitura imediata apresenta uma subordinação da educação à economia ou ao trabalho abstrato; mais do que isso, tanto a economia capitalista como o trabalho abstrato são trazidos para dentro da esfera educacional e da escola na condição de elementos centrais para dar significado a esta esfera social e a esta instituição, bem como para o exercício da tão falada cidadania. Nesse movimento de incorporação do trabalho abstrato e socialmente necessário, na concepção de Marx, a lei atual faz, de forma mais inteligente e persuasiva, o que a Lei ${ }^{\circ}$ 5.692/ 71, do governo militar-autoritário, fizera: reduzir a formação geral à específica ou transformar todo o ensino secundário em profissionalizante. Pode-se ler no documento:

O trabalho é o contexto mais importante da experiência curricular no ensino médio, de acordo com as diretrizes traçadas pela $\mathrm{LDB}$ em seus artigos 35 e 36. O significado desse destaque deve ser devidamente considerado: na medida em que o ensino médio é parte integrante da educação básica e que o trabalho é princípio organizador do currículo, muda inteiramente a noção tradicional de educação geral acadêmica ou, melhor dito, academicista. $\mathrm{O}$ trabalho já não é mais limitado ao ensino profissionalizante. Muito ao contrário, a lei reconhece que nas sociedades contemporâneas 
todos, independentemente de sua origem ou destino socioprofissional, devem ser educados na perspectiva do trabalho enquanto uma das principais atividades humanas, enquanto campo de preparação para escolhas profissionais futuras, enquanto espaço de exercício de cidadania, enquanto processo de produção de bens, serviços e conhecimentos com as tarefas laborais que lhes são próprias. A riqueza do contexto do trabalho para dar significado às aprendizagens da escola média é incomensurável. Desde logo na experiência da própria aprendizagem como um trabalho de constituição de conhecimentos, dando à vida escolar um significado de maior protagonismo e responsabilidade. Da mesma forma o trabalho é um contexto importante das ciências humanas e sociais, visando compreendêlo enquanto produção de riqueza e forma de interação do ser humano com a natureza e o mundo social. Mas a contextualização no mundo do trabalho permite focalizar muito mais todos os demais conteúdos do ensino médio. (Brasil, 1998, p. 58; grifos nossos)

Argumento, sobre esta questão, que tal movimento, já realizado pelos tecnocratas elaboradores dos Planos Setoriais de Educação e Cultura - setoriais porque subordinados aos Planos Nacionais de Desenvolvimento -, do governo militar-autoritário, é uma dimensão da construção do novo pacto social mundializado, para o que é estrutural a participação da esfera educacional na sua configuração sob o já referido "pan-paradigma”. E, como afirma Mézáros (2002), é esse movimento que resulta do presente metabolismo social, quando o capital se póe em esferas nas quais ele se encontrava ausente, especialmente no âmbito da política e concretamente no Estado tal como buscamos mostrar.

No item $O$ ensino médio no mundo: Transformação acelerada das Diretirzes..., enfatiza-se a necessidade de a ampliação e cobertura do ensino médio no Brasil estarem se realizando simultaneamente a semelhantes iniciativas em todo o mundo. Isso, seria uma decorrência de esse nível de ensino possuir características específicas, tais como somar ${ }^{7}$ as funçôes propedêuticas e de terminalidade, e por isso tem sido o nível mais afetado do sistema de ensino, no que se refere ao fato de que, entre seus objetivos, destacam-se os de "exercer a cidadania e de organizar o trabalho, impostos pela nova geografia política do planeta, pela globalização econômica e pela revolução tecnológica".

Do que os reformistas depreendem, entre outros fatores abaixo citados, a necessidade de integração e adaptação dos indivíduos à sociedade e ao cambiante mundo do trabalho, por meio do desenvolvimento de competências e habilidades. 
A facilidade de acessar, selecionar e processar informações está permitindo descobrir novas fronteiras do conhecimento nas quais este se revela cada vez mais integrado. Integradas são também as competências e habilidades requeridas por uma organização da produção na qual criatividade, autonomia e capacidade de solucionar problemas serão cada vez mais importantes, comparadas à repetição de tarefas rotineiras. E mais do que nunca, há um forte anseio de inclusão e de integração sociais como antídoto à ameaça de fragmentação e segmentação. Essa mudança de paradigmas no conhecimento, na produção e no exercício da cidadania - colocou em questão a dualidade, mais ou menos rígida dependendo do país, que presidiu a oferta de educação pós-obrigatória. Inicia-se assim em meados dos anos 80 e primeira metade dos 90 um processo ainda em curso, de revisão das funções tradicionalmente duais da educação secundária, buscando um perfil de formação do aluno mais condizente com as características da produção pós-industrial. $\mathrm{O}$ esforço de reforma foi assim, na sua motivação inicial, fortemente referenciado nas mudanças econômicas e tecnológicas. (Brasil, 1998, p. 19-20; grifos nossos)

Julgamos louvável a preocupação em referenciar a reforma do ensino médio nas radicais transformações em curso no mundo em geral, e, em particular, no Brasil, porém tal referência deve ser contemplada em toda sua complexidade e não somente com base nas mudanças econômicas e tecnológicas. Em acréscimo, tal referência não deve ser construída por meio de análise bastante linear: desenvolvimento científico e tecnológico, mudanças econômicas e sociais, mudanças na organização do trabalho, implicando novas demandas para a formação, do que decorreriam as orientações para a reforma desse nível de ensino.

Outro aspecto, que parece decorrer da redução da formação geral à específica, como indicado anteriormente, consiste no estabelecimento da pretensa unidade entre os dois tipos de formação (como enfatiza o documento), pois, agora, agregam-se os "ideais do humanismo e da diversidade”. A redução e a mercantilização da esfera educacional tornam-se unidades, com a aparente articulação com o humanismo e a diversidade. Pelo que se expôs até aqui, trata-se de um humanismo caritativo e de uma diversidade adaptativa e produtora de consenso, decorrente da formação humana por meio do desenvolvimento cognitivo, portanto, como já analisado, a-histórico (Cf. Brasil, 1998, p. 20). Em contrapartida, torna-se mais uma vez explícita a inspiração da reforma no movimento mundial, em grande medida liderado pela UNESCO.

A União Européia manifestou-se de forma contundente em favor da unificação do ensino médio, mas alerta para a necessidade de considerar 
outras necessidades além das que são sinalizadas pela organização do trabalho. E busca sustentação para sua posição no pensamento do próprio empresariado europeu: a missão fundamental da educação consiste em ajudar cada indivíduo a desenvolver todo o seu potencial e a tornar-se um ser humano completo, e não um mero instrumento da economia; a aquisição de conhecimentos e competências deve ser acompanhada pela educação do caráter, a abertura cultural e o despertar da responsabilidade social.

A mesma orientação segue a UNESCO no relatório da Reunião Internacional sobre Educação Para o Século XXI. Esse documento apresenta as quatro grandes necessidades de aprendizagem dos cidadãos do próximo milênio às quais a educação deve responder: aprender a conhecer, aprender a fazer, aprender a conviver e aprender a ser. E insiste que nenhuma delas deve ser negligenciada. (Brasil, 1998, p. 21; grifos nossos)

Pensamos não haver dúvidas, com base no enunciado acima, quanto ao fato de que as autoridades políticas brasileiras e os especialistas construtores da reforma do ensino médio não só se inspiraram no movimento liderado pela UNESCO, mas também dele eram atores, produzindo na esfera educacional o "pan-paradigma", na condição de parte orgânica da construção do pacto social mundializado, dadas as transformações dos elementos que fundam a reprodução social da vida humana no marco da transição da forma histórica do capitalismo protagonizada pelo Estado de Bem-Estar Social para a forma protagonizada pelo Estado Gestor atual.

A análise dos Parâmetros Curriculares Nacionais para o Ensino Médio (PCNEM) revela-nos o trabalho sério e competente dos reformistas, posto que a tradução das Diretrizes... para uma necessária Base Comum Nacional... é muito coerente e mantém uma relação de identidade em toda a sua constituição, especialmente nas suas Bases Legais, Ciências Humanas e suas Tecnologias, Ciências da Natureza, Matemática e suas Tecnologias e Linguagens, Códigos e suas Tecnologias. Os supostos do neopragmatismo articulados com os supostos cognitivos, adaptativos e instrumentais fazem-se presentes, buscando concretizar a suposta unidade entre formação geral e específica, colocando a economia e o trabalho como esferas que foram transportadas em geral para as esferas sociais, antes não organizadas diretamente por tais elementos fundacionais, em particular para a educação e a instituição escolar.

Nas Bases Legais dos PCNEM, ancorados na Lei de Diretrizes e Bases da Educação Nacional, a unidade suposta entre formação geral e específica já se põe na condição de dois pilares centrais, que, na sequiência, desvelam a inserção da economia e do trabalho abstrato 
como organizadores desse nível de ensino. Pode-se ler, nesse tópico dos PCNEM, que, na "perspectiva da nova Lei, o Ensino Médio, como parte da educação escolar, 'deverá vincular-se ao mundo do trabalho e à prática social' (Art. $1^{\circ}, \$ 2^{\circ}$, da Lei no 9.394/96). Essa vinculação é orgânica e deve contaminar toda a prática educativa escolar" (grifos nossos).

O genial pensador italiano Antonio Gramsci, em seu ensaio Americanismo e fordismo, ao analisar a possibilidade de transformações profundas na Europa, por meio da introdução de uma nova base produtiva e de novas formas de produção e reprodução da sociedade da época, assinalava a resistência que tal movimento encontraria para consolidar-se no Velho Continente do início do século XX, no contexto de trânsito do "individualismo econômico para uma economia programática”.

Gramsci indicava um itinerário analítico, no qual os processos sociais e culturais produzidos por instituições cristalizadas historicamente na Europa, que se realizavam nas práticas sociais dos indivíduos, não podiam ser plenamente entendidos se desvinculados das transformações na base produtiva. Criticava a cultura européia por desejar "a mulher embriagada e o tonel cheio", donde derivaria toda a resistência à introdução de novo ser social e uma nova forma de produção material da vida humana. Insistia na compreensão do processo de ruptura, e, ao mesmo tempo, de continuidade histórica do modo de produção capitalista a partir da articulação da economia com a materialidade instituída das relações sociais. Seriam necessárias a compreensão das mudanças sociais e a produção de um novo homem, dos processos de formação do sujeito no âmbito do trabalho e dos processos de reprodução social (Cf. Gramsci, 1988, p. 396).

Prentendemos, com nosso texto, percorrer esse itinerário para tentar mostrar a natureza da unidade proposta nas Diretrizes... e nos Parâmetros..., que competentemente realiza esse movimento desde uma perspectiva a-histórica e por meio da instrumentalidade, da cognição exclusiva e da busca do consenso. Ao mostrarmos as razões de emergência do neopragmatismo, da razão instrumental e da psicologia cognitivista com base na análise do trânsito do fordismo à acumulação flexivel, queremos mostrar as relações orgânicas entre as mundanças na economia capitalista e no trabalho abstrato e as transformações nas estruturas sociais. Para, a partir de então, podermos compreender a reforma educacional para o ensino médio e a proclamada unificação entre o propedêutico e o profissional. 
A suposta identificação das distintas formações desvela-se na decorrência do suposto legal da LDB anteriormente citado. A "formação da pessoa, de maneira a desenvolver valores e competências necessárias à integração de seu projeto individual ao projeto da sociedade em que se situa"; "o aprimoramento do educando como pessoa humana, incluindo a formação ética e o desenvolvimento da autonomia intelectual e do pensamento crítico"; destaca-se aqui, pelo que já se escreveu, o caráter de uma autonomia para a integração e a formação de um pensamento crítico-funcionalista, na medida em que se toma a realidade social como dada e faz-se a crítica para melhorar a situação do indivíduo e da própria realidade social capitalista em seu presente estágio. Parafraseando Rorty, "usando o mundo e os guias seguros para o sucesso individual e o bom funcionamento do mundo". Por outro lado, ainda nesse tópico dos PCNEM, pode-se ler sobre a necessária "preparação e orientação básica para a sua integração ao mundo do trabalho, com as competências que garantam seu aprimoramento profissional e permitam acompanhar as mudanças que caracterizam a produção no nosso tempo" e "o desenvolvimento das competências para continuar aprendendo, de forma autônoma e crítica, em níveis mais complexos de estudos". Para tais itens vale lembrar o comentário feito acima, isto é, a formação para encontrar guias seguros que o mundo mostraria aos indivíduos, e que nos assegurariam nosso bem-estar.

Quanto às áreas, destacam-se novamente a seriedade e a competência da equipe na definição de seus objetivos, a relação que cada área mantém com as Diretrizes..., com as Bases Legais... dos PCNEM e com as demais áreas, relaçôes coerentes e de identidade com todos os documentos oficiais para esse nível de ensino, bem como os demais níveis e modalidades. No entanto, é interessante mostrar, a título de exemplo, como os supostos já indicados e analisados reiteradamente neste artigo se expressam em uma das áreas dos Parâmetros.... $\mathrm{Na}$ área de Ciências Humanas e suas Tecnologias, pode-se depreender com clareza o que afirmamos acima, isto é, como a ciência se torna instrumental e engajada na proposta pedagógica da reforma do ensino médio. Destaca-se ainda nesta citação, novamente, o chamamento de autoridade das agências multilaterais. Quanto ao "Relatório Delors sobre a Educação para o Século XXI”, nele podemos ler:

Mesmo considerando os obstáculos a superar, uma proposta curricular que se pretenda contemporânea deverá incorporar como um dos seus 
eixos as tendências apontadas para o século XXI. A crescente presença da ciência e da tecnologia nas atividades produtivas e nas relaçôes sociais, por exemplo, que, como conseqüência, estabelece um ciclo permanente de mudanças, provocando rupturas rápidas, precisa ser considerada. Ao fazê-lo, o documento reinterpreta os princípios propostos pela Comissão Internacional sobre Educação para o Século XXI, da UNESCO, amparados no aprender a conhecer, no aprender a fazer, no aprender a conviver $\mathrm{e}$ no aprender a ser. A estética da sensibilidade, que supera a padronização e estimula a criatividade e o espírito inventivo, está presente no aprender a conhecer e no aprender a fazer, como dois momentos da mesma experiência humana, superando-se a falsa divisão entre teoria e prática. A política da igualdade, que consagra o Estado de Direito e a democracia, está corporificada no aprender a conviver, na construção de uma sociedade solidária através da ação cooperativa e não-individualista. A ética da identidade, exigida pelo desafio de uma educação voltada para a constituição de identidades responsáveis e solidárias, compromissadas com a inserção em seu tempo e em seu espaço, pressupõe o aprender a ser, objetivo máximo da ação que educa e não se limita apenas a transmitir conhecimentos prontos. Tais princípios são a base que dá sentido à área de Ciências Humanas e suas Tecnologias. (Brasil, 1999, p. 8; grifos nossos)

\section{Conclusão}

O excerto acima permite-nos ao menos inferir, dado o argumento de autoridade, sobre a orgânica participação de nossas autoridades políticas e especialistas educacionais em suas áreas no movimento mundial de construção do "pan-paradigma educacional". $\mathrm{O}$ que nos indica a força da participação desses intelectuais na construção da reforma, bem como o papel de uma ciência engajada nesse processo, com profundas influências sobre a função que as universidades passam a exercer depois da reforma da educação superior em curso já na sua prática, articulada com a de outros níveis e modalidades de ensino.

As instituições de educação superior, quando consolidadas as suas novas faces, à luz da reforma do Estado e das mudanças na produção, além de assemelharem-se a uma empresa prestadora de serviços para o mercado, por meio do processo de sua mercantilização (Cf. Sguissardi e Silva Jr., 2001) - resultado da inserção do capital na esfera pública em geral -, também se tornam um aparelho privado de hegemonia, eficiente na legitimação do "pan-paradigma educacional" e do pacto social mundializado. 
Como anunciamos neste texto, depois de mostrar as propostas do governo de Fernando Henrique Cardoso e seus resultados para o país no âmbito da economia, do social e, especialmente, no da educação, o objetivo central do artigo consistia em responder à seguinte indagação central: Quais as derivações políticas da reforma educacional para o ensino médio e o seu significado para a formação humana?

Para isso, buscamos mostrar como se deu o movimento de construção de novo pacto social mundializado, para o que concorreria de forma contundente, nas palavras de Bueno (2000), a produção de um "pan-paradigma educacional" centrado na ausência do debate das propostas para o ensino médio e no caráter "infalível" dessas propostas. Isso era parte da demanda vinda das mudanças nas estruturas sociais, diante das transformações nos elementos fundantes da reprodução social no presente momento do capitalismo no Brasil, ainda que tivéssemos claro o caráter contraditório da reforma diante das necessárias mediações no movimento, que se origina na produção da proposta, sua sistematização e aprovação no âmbito político-normativo pelo Estado, até a prática escolar no cotidiano (Cf. Popkewitz, 1994, especialmente o capítulo V).

Nesse processo de mediações, procuramos mostrar as razões da emergência do neopragmatismo como fundamento para a construção do pacto social mundializado, dada a hegemonia dos Estados Unidos da América (Cf. Popkewitz, 1994, e Mézáros, 2002) na reordenação da ordem econômica mundial, e no âmbito da construção do "pan-paradigma educacional", bem como a emergência do cognitivismo, da razão instrumental baseada em uma ciência engajada - que auxilie os indivíduos "a usar e dar sentido ao mundo" (Rorty) - com vistas à adaptação do ser social às mudanças, em curso há mais de três décadas, do capitalismo no Brasil e no mundo.

Isso implicou um novo conteúdo histórico para a cidadania, caracterizada por: um acentuado individualismo, uma exacerbada competitividade, uma busca de adaptação às muitas divisões sociais que emergiram nesse momento histórico, uma busca de adaptação ao estratificado e precarizado mercado de trabalho, uma adaptação aos trabalhos mais indignos que resultaram do processo anterior (veja-se, por exemplo, os cursos oferecidos pelo Programa Nacional de Qualificação Profissional - PLANFor -, bem como a própria criação do programa e seus objetivos) e, diante de tal adaptação, 
da degradação do trabalho e do enfraquecimento de instituições e organizaçôes políticas de mediação entre o Estado e a sociedade civil, da incapacidade de reivindicação do cidadão e do trabalhador. O que certamente é resultado e consolidação do novo paradigma político, que estabelece novas práticas sociais e orienta as políticas públicas em geral, em particular para a educação.

O que significam então as políticas para o ensino médio decorrentes da reforma para esse nível de ensino e suas conseqüências para a formação do ser social?

Elas são parte do movimento de reforma educacional no Brasil - na condição de dimensão orgânica das reformas educacionais em todo o mundo -, bem como decorrência da reforma do Estado, transformado em Estado Gestor (forte no plano nacional e submisso no âmbito internacional). Isso, por sua vez, relaciona-se diretamente com o novo paradigma político ancorado nos supostos neopragmáticos, que se expressam na educação pela adaptação cognitivista expressa na pedagogia que orientou a reforma para o ensino médio. Destaca-se que tais dimensões são parte orgânica do movimento de reorganização da economia mundial e do trabalho, que impõe um novo metabolismo social, e, com isso, novas estruturas sociais, para o que concorre a educação, especialmente, como indicado, para o ensino médio em face de suas peculiaridades de possuir como objetivos a formação geral e propedêutica e a formação específica para a terminalidade da trajetória escolar do indivíduo.

Destaca-se, ainda, que a reforma do ensino médio se encontra em curso no Brasil desde os anos de 1980, quando o governo brasileiro adere ao consensus, o que se pode depreender dos parágrafos acima, que buscam ser uma síntese dos argumentos expostos neste artigo. Basta para isso atentarmos para o que escreve Fiori (1995):

A ilustrativa figura de linguagem [Consenso de Washington], hoje de domínio público internacional, refere-se a um plano único de ajustamento das economias periféricas, chancelado pelo FMI e pelo BIRD em mais de 60 países de todo o mundo, configurando uma estratégia de homogeneização das políticas econômicas nacionais, operadas, em alguns casos, como em boa parte da África - começando pela Somália, no início de 1980 -, diretamente pelos próprios técnicos daquelas agências; em outros, como exemplificar, na Bolívia, na Polônia e mesmo na Rússia até há bem pouco tempo, com a ajuda de economistas universitários 
norte-americanos; e, finalmente, em países com corpos burocráticos mais estruturados, pelo que Williamson apelidou de technopols, ou seja, economistas capazes de somar ao perfeito manejo do seu mainstream (evidentemente neoclássico e ortodoxo) a capacidade política de implementar nos seus países a mesma agenda do consensus, como é ou foi o caso, para exemplificar, de Aspe, Salinas e Zedillo, no México; de Cavallo, na Argentina; de Yegor Gaidar na Rússia; de Lee Teng-hui, em Taiwan; Manmohan Singh, na Índia; ou mesmo Turgut Ozal, na Turquia; e, a despeito de tudo, Zélia e Kandir, seguidos de Malan, Arida, Bacha e Franco, no Brasil. (Fiori, 1995, p. 234)

A esse compromisso assumido pelo Estado brasileiro - que é, concretamente, o governo em momento histórico determinado - articularam-se os demais compromissos para a área social, incluindo aí os tantos compromissos assumidos para a educação, que orientaram a reforma educacional no Brasil, como fica explícito nos documentos oficiais, no caso, do ensino médio, com citações, remissóes e o reiterado apelo a argumentos de autoridade representados pela constante referência aos documentos produzidos no movimento mundial liderado pela UNESCO e pelas agências multilaterais da esfera econômica, com destaque para o Banco Mundial.

Todo esse processo, com marco em 1990, com a Declaração Mundial de Educação para Todos, e sua expressão no Brasil, o Plano Decenal de Educação para Todos, já era concretamente a primeira fase da reforma educacional brasileira, particularmente para o ensino médio, em face do que acima indicamos. Finalmente, gostaríamos de especular, diante do quadro que apresentamos ao longo do texto, sobre as conseqüências para a formação humana, com a consolidação em curso da reforma educacional para o ensino médio. Diante da contradição entre a estratificação do mercado de trabalho, e da precarização deste último, e a ideologia da instrumentalidade, adaptação e consenso presente no ensino médio, nossos jovens parecem deixar de acreditar na escola como forma de ascensão social e inserção no mercado de trabalho, ao contrário do que afirmam os reformadores. Do que se pode levantar a hipótese de tantos problemas que a instituição escolar pública vem enfrentando, especialmente a violência na escola. Em contrapartida, diante das características desse nível de ensino, as classes médias, se tiverem condições orçamentárias, e as elites, com certeza, parecem fugir ainda mais da esfera pública escolar, ficando esta última para os desvalidos sociais. $\mathrm{O}$ ensino médio, ao contrário do que dizem os reformadores, tende a acentuar as desigualdades 
sociais, em vez de possibilitar a eqüidade, de um lado, e, de outro, conforma cada indivíduo em sua divisão social: a educação pública nunca fora tão perversa. No âmbito do mercado de serviços, possibilita um espaço enorme para privatização da esfera educacional no ensino médio. Mas para todas as divisões sociais, radicalizando as desigualdades, as políticas públicas para o ensino médio estão formando o cidadão do século XXI, como propõe o Relatório de Delors: o Cidadão Produtivo: útil, mudo, competitivo e solitário.

\section{Recebido e aprovado em agosto de 2002.}

\section{Notas}

1. Cf. Valdemar Sguissardi e João dos Reis Silva Jr., "Reforma do Estado e da educação superior no Brasil”, em Valdemar Sguissardi, Avaliação universitária em questão, Campinas: Autores Associados, 1997.

2. Sem reformas não há desenvolvimento, Folha de S. Paulo, São Paulo, 8/4/96, Caderno 1, p. 7.

3. Os países emergentes reiteraram, em 1993, o compromisso de atender as necessidades básicas de aprendizagem e convocam "as instituiçôes financeiras internacionais para que, sob o prisma de ajustes estruturais, reconheçam a educação como investimento crítico (...)" (Declaração de Nova Delhi, 16 de dezembro de 1993; grifos nossos).

4. Um dos principais articuladores da tão propalada reforma educacional do Estado de Minas Gerais, financiada em grande parte pelo Banco Mundial, bem como avaliada segundo seus princípios para reformas educacionais (Cf. Torres, 1996).

5. Os pragmatistas limitam-se a oferecer respostas tão vagas e imprecisas porque o que eles esperam não é que o futuro se conforme a um plano, ou satisfaça uma teleologia imanente, mas sim que o futuro nos surpreenda e nos estimule. Assim como os fãs da vanguarda vão às galerias de arte na esperança de serem surpreendidos, e não de terem alguma de suas expectativas satisfeitas, essa divindade antropomórfica celebrada por James, e mais tarde por A. N. Whitehead e Charles Harsthorne, espera ser supreendida e encantada pelo produto mais recente da evolução, tanto biológica quanto cultural. Pedir a um pragmatista seu projeto de futuro equivale a pedir a Whitman para esboçar o que encontraremos ao final de sua ilimitável perspectiva democrática. A perspectiva, e não o ponto final, é o que importa. Richard Rorty, "Verdade sem correspondência com a realidade", em Cristina Magro e Antonio Marcos Pereira (Orgs.), Pragmatismo: A filosofia da criação e da mudança, Belo Horizonte: Editora da UFMG, 2000, p. 28; grifos nossos.

6. O ser humano é, aprende e se forma por meio de suas atividades em geral, dentre elas a educacional e a escolar. Este "pilar" de Delors expressa os supostos cognitivistas e adaptativos, que se põem ao pan-paradigma para a educação do século XXI.

7. Trata-se, na verdade, de juntar as funções propedêuticas e de terminalidade, buscando dar uma aparência de unidade produzida por articulação orgânica das duas.

8. União Européia. Livro branco - Ensinar e aprender: rumo à sociedade cognitiva. 
Referências bibliográficas

ANDERSON, P. Balanço do neoliberalismo. In: Gentili, P.; SADER, E. (Orgs.). Pós-neoliberalismo: as políticas sociais e o Estado democrático. Rio de Janeiro: Paz \& Terra, 1995.

BOURGUINAT, H. Finance internationale. Paris: puF, 1992.

BRASIL. Lei de Diretrizes e Bases da Educação Nacional. Lei 9.394/96, de 20 de dezembro de 1996. Estabelece as diretrizes e bases da educação nacional. Diário Oficial da União, Brasília, DF, 23 dez. 1996.

BRASIL. Ministério da Educação e do Desporto. Plano Decenal de Educação para Todos: 1993-2003. Brasília, DF: MEC, 1994.

BRASIL. Ministério da Educação e do Desporto. Secretaria de Educação Média e Tecnológica. Diretrizes curriculares nacionais para o ensino médio. Brasília, DF: MEC/SEMTEC, 1998.

BRASIL. Ministério da Educação e do Desporto. Secretaria de Educação Média e Tecnológica. Parâmetros curriculares nacionais para o ensino médio. Brasília, DF: MEC/SEMTEC, 1999.

BUENO, M.S.S. Orientações nacionais para a reforma do ensino médio: dogma ou liturgia. Cadernos de Pesquisa, São Paulo, n. 109, p. 7-24, mar. 2000.

CHESNAIS, F. A mundialização do capital. São Paulo: Xamã, 1996.

COMISIÓN ECONOMICA PARA AMERICA LATINA Y EL CARIBE. Educación y conocimiento: eje de la transformación productiva com equidad. Santiago de Chile: cepal/orealc, 1992.

CORAGGIO, J.L. Propostas do Banco Mundial para a educação: sentido oculto ou problemas de concepção? In: WARDE, M.J. et al. O Banco Mundial e as politicas educacionais. São Paulo: Cortez; Ação Educativa, 1996.

DELORS, J. Educação: um tesouro a descobrir. São Paulo: Cortez; Brasília, DF: MEC; UNESCO, 1996. 
DESIGUALDADE social. Correio da Paraíba, João Pessoa, 15 jan. 2002, Caderno 1, p. 2.

DUNNING, J.H. Explanning international production. London: Unwin Hyman, 1988.

FERRETTI, C.J.; SILVA JR., J.R. Educação profissional em uma sociedade sem emprego. Cadernos de Pesquisa, São Paulo, n. 109, p. 43-66, 2000.

FIORI, J.L. Em busca do dissenso perdido. Rio de Janeiro: Insight, 1995.

GRAMSCI, A. Maquiavel, a politica e o Estado moderno. Rio de Janeiro: Civilização brasileira, 1988.

MÉSZÁROS, I. Para além do capital: rumo a uma teoria da transição. Campinas: Editora da UnICAMP; São Paulo: Boitempo, 2002.

MICHALET, C.A. Le capitalisme mondial. Paris: PUF, 1985.

MORAES, M.C.M. Ceticismo epistemológico, ironia complacente: até onde vai o neopragmatismo rortyano. Educação nas Ciências, Ijuí, n. 1, p. 157-189, jan./jun. 2001.

POPKEWITZ, T.S. Sociología politica de las reformas educativas. La Coruña: Fundación Paideia; Madrid: Morata, 1994.

RORTY, R. Verdade sem correspondência com a realidade. In: Magro, C.; Pereira, A.M. (Orgs.). Pragmatismo: a filosofia da criação e da mudança. Belo Horizonte: UfMG, 2000.

SEM reformas não há desenvolvimento. Folha de S. Paulo, São Paulo, 8 abr. 96, Caderno 1, p. 7.

SGUISARDI, V.; SILVA JR., J.R. Reforma do Estado e da educação superior no Brasil. In: SGUissardi, V. Avaliação universitária em questão. Campinas: Autores Associados, 1997.

SGUISSARDI, V.; SILVA JR., J.R. Novas faces da educação superior no Brasil: reforma do Estado e mudanças na produção. São Paulo: Cortez; Bragança Paulista: EDUsf, 2001.

TORRES, R.M. "Melhorar a qualidade da educação básica? As estratégias do Banco Mundial”. In: Haddad, S.; De Tommasi, 
L.; Warde, M.J. (Orgs.). O Banco Mundial e as politicas educacionais. São Paulo: Cortez; Ação Educativa, 1996.

UNESCO. Declaração de Nova Delhi. Nova Delhi, 1993.

UNESCO. Declaração mundial sobre educação para todos: satisfação das necessidades básicas de aprendizagem. Jomtien, 1990. 